\title{
RESEARCH ON THE INFLUENCE OF MILD STEEL DAMPERS ON SEISMIC PERFORMANCE OF SELF-RESETTING PIER
}

\author{
Mengqiang Guo and Yanli Shen
}

\author{
University of Hebei Engineering, Faculty of Civil Engineering, Handan, Hebei, China; \\ guo1933619417@163.com, shenyanli@hebeu.edu.cn
}

\begin{abstract}
In order to improve the energy consumption capacity of the assembled self-resetting pier, the mild steel damper is added to the prefabricated self-resetting pier to form a prefabricated selfresetting pier with an external mild steel damper. Two sets of pier models were established by numerical simulation. On the basis of verifying the correctness of the traditional prefabricated selfresetting pier model, the two sets of pier models were subjected to low-cycle reciprocating loading to study the influence of the mild steel damper yield strength parameters and the pier axial compression ratio parameters on the seismic performance of the pier structure. The results show that compared with traditional prefabricated self-resetting piers, the hysteresis curve of self-resetting piers with mild steel dampers is fuller, and energy consumption and bearing capacity are greatly improved. With the increase of the yield strength of the mild steel damper, the energy consumption capacity will decrease when the loading displacement is less than $25 \mathrm{~mm}$, but the overall energy consumption capacity will increase. As the axial compression ratio of the pier column increases, the bearing capacity and energy consumption capacity of the structure increase significantly, but the impact is not obvious when the axial compression ratio exceeds 0.052 .
\end{abstract}

\section{KEYWORDS}

Self-resetting pier, Mild steel damper, Axial compression ratio, Seismic performance

\section{INTRODUCTION}

Compared with cast-in-place concrete piers, fabricated self-resetting piers have the advantages of good seismic performance, high post-earthquake repairability, and low damage. In particular, the combination of damping technology and self-resetting pier design forms a layered protection. The bridge system that can eliminate the plastic hinge and quickly restore its function after an earthquake has important research value. Mander et al [1] first introduced the idea of selfresetting structure in the design of bridge piers, using unbonded prestressed steel bars to improve the seismic performance of the bridge piers. The pseudo-static test results showed that the prefabricated self-resetting bridge piers have small residual displacements, but weak energy consumption. In order to improve the energy dissipation capacity of bridge piers, Solberg et al [2] proposed to install energy dissipation steel bars to improve the seismic performance of bridge piers. The pseudo-static test results showed that energy dissipation steel bars increased the energy dissipation capacity of bridge piers. Marriott et al [3-4] proposed to install an external energy dissipation device to improve the post-earthquake recovery of the self-resetting pier. The pseudostatic and pseudo-dynamic test results show that the new prefabricated self-resetting pier has higher bearing capacity and energy consumption, and easy to repair after an earthquake. Trono et al [5] confirmed that self-resetting piers have obvious advantages in damage and residual displacement through shaking table tests. Guo Jia, Xin Kegui et al [6-7] expounded the working principle of prefabricated self-reset bridge pier test. Haitham [8] performed a numerical simulation on the performance of the fabricated bridge pier under reciprocating load and verified the influence of the 
concrete constitutive model on the simulation results. Bu et al [9] conducted pseudo-static tests on 5 circular cross-section piers. The test results showed that compared with bonded prestressed tendons, unbonded prestressed tendons have less prestress loss and more sustainable and effective prestress. Wang Junwen et al [10] conducted a pseudo-static test on a hollow concrete pier and 3 precast and assembled hollow piers with prestressed sections. The test results showed that the unbonded prestressed tendons reduced the residual displacement of the structure, but the energy dissipation capacity decline. Ge Jiping [11] conducted a pseudo-static test study on prefabricated self-resetting bridge piers. The study showed that the bottom of the pier and the cap were separated and swayed. Although the bottom damage of the pier column was reduced, the overall energy consumption was reduced. Guo et al [12] tried to set up replaceable external energy-consuming devices. Research shows that different energy-consuming device parameters have a certain impact on the seismic performance of bridge pier structures. In summary, the traditional prefabricated selfresetting piers have good self-reset capability and small residual displacement, but they have poor energy consumption and they are not easy to repair after an earthquake. Fabricated self-resetting piers with external mild steel dampers have the advantages of good energy consumption and easy repair after earthquakes. It is necessary to conduct more in-depth research on fabricated selfresetting piers with additional mild steel dampers.

This research proposes a fabricated self-resetting pier structure with mild steel dampers. The establishment of a refined numerical model and the validation of the validity of the numerical simulation are carried out to study the seismic performance of fabricated self-resetting piers with mild steel dampers, and the influence of different yield strength parameters and different axial compression ratio parameters on the seismic performance of the structure.

\section{METHODS}

\section{Fabricated Self-resetting Pier Structure with Mild Steel Damper}

An external mild steel damper is added to the foundation of the traditional prefabricated selfresetting pier. The pier and the cap are separated. The mild steel dampers are symmetrically arranged at the centre of the two sides of the pier at a 45-degree angle along the transverse direction. The damper can effectively transfer stress and avoid slippage of the structure. The structure diagram of the assembled self-resetting pier with external mild steel damper as shown in Figure 1.

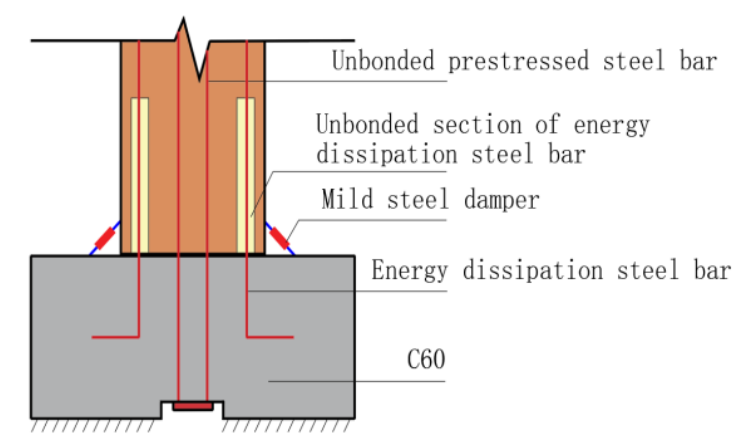

Fig. 1 - Structure Drawing of Prefabricated Self-Resetting Pier with External Mild Steel Damper

\section{Basic Structure and Working Principle of Mild Steel Damper}

The structure diagram of the mild steel damper is shown in Figure 2 and the main component size diagram is shown in Figure 3. The mild steel damper is mainly composed of 1 . shaft sleeve hinge support, 2. shaft hinge support, 3. high-strength bolts, 4. mild steel rod, 5 . shaft sleeve, and 6. shaft. 


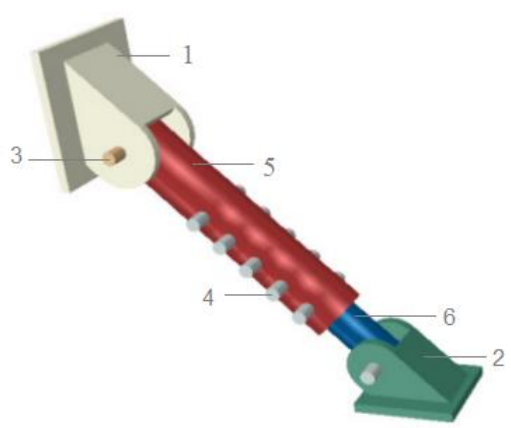

(a) Assembly Drawing

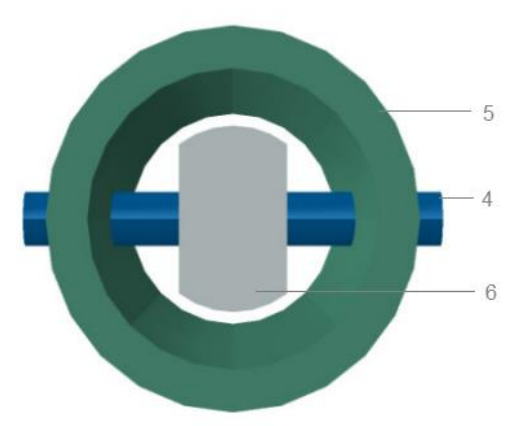

(b) Sectional Drawing

Fig. 2 - Structural Diagram of Mild Steel Damper

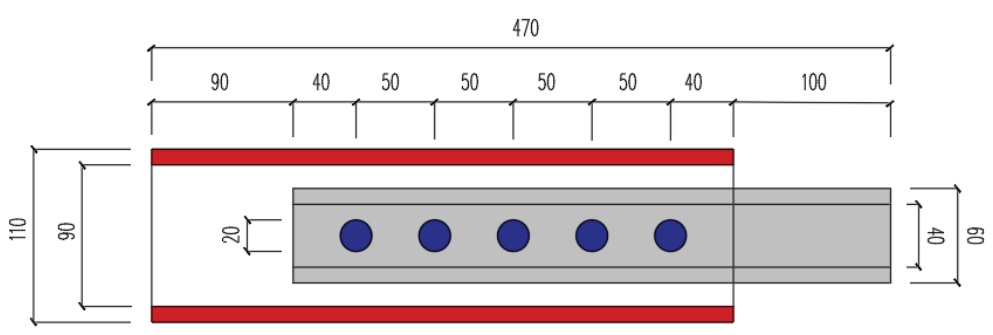

Fig. 3 - The Main Component Dimension Diagram of Mild Steel Damper

The shaft hinge support 2 and the shaft sleeve hinge support 1 are consolidated with the bridge pier structure through high-strength bolts. The shaft 6 and the shaft sleeve 5 are respectively hinged with the shaft hinge support 2 and the shaft sleeve hinge support 1 through the high-strength bolt 3 , so that the damper only receives axial force. The shaft 6 is arranged inside the shaft sleeve 5 , the shaft and the shaft sleeve are provided with five one-to-one corresponding circular holes along the axial direction, and a soft steel rod 4 penetrates between each corresponding shaft sleeve circular hole and the shaft circular hole. Except for mild steel bars, other parts are made of Q345 high-strength steel. When the mild steel damper is deformed, the sleeve and the shaft move to squeeze the mild steel rod to yield and consume energy.

\section{Yield Mechanism of Mild Steel Damper Prior to Energy Dissipation Steel Bar}

Under the condition of ignoring the second-order effect of the bridge pier, the schematic diagram of the corner between the bottom of the bridge pier and the cap under the action of earthquake as shown in Figure 4. 


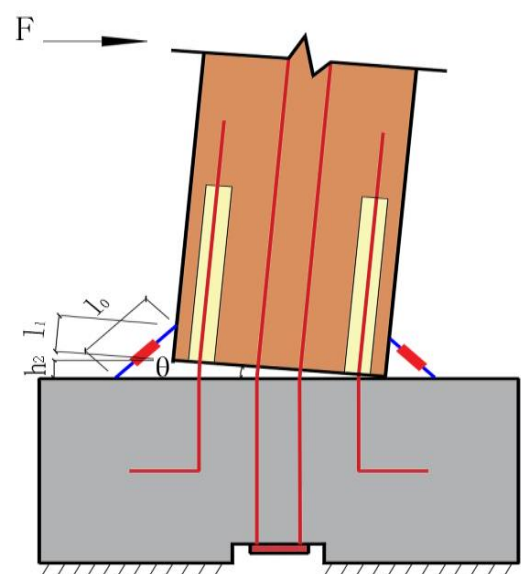

Fig. 4 - Schematic Diagram of Assembled Self-Resetting Pier with External Mild Steel Damper

When an angle of $\theta$ occurs between the bottom of the pier and the cap under the action of an earthquake load, $\varepsilon_{0}$ is the deformation of the energy dissipating steel bar, as Equation (1).

$$
\varepsilon_{0}=(b-c) \sin \theta
$$

$h_{2}$ is the rising height of the left edge of the bottom of the pier, as Equation (2)

$$
h_{2}=b \sin \theta
$$

$l_{2}$ is the deformed length of the damper, as Equation (3)

$$
\left(l_{1} \cos \theta+h_{2}\right)^{2}+\left(l_{1} \sin \theta+b-b \cos \theta+l_{1}\right)^{2}=l_{2}{ }^{2}
$$

$\varepsilon_{1}$ is the deformation of the damper, as Equation (4)

$$
\varepsilon_{1}=l_{2}-l_{0}
$$

In the above Equation, $l_{0}$ is the initial length of the damper, $b$ is the transverse dimension of the pier, and $c$ is the distance between the energy dissipating steel bar and the edge of the pier. Generally, $\varepsilon_{1}>\varepsilon_{0}$, because the greater the radius, the greater the arc length under the same corner. When satisfied: ( $\varepsilon_{1}$-Yield displacement of damper $>\varepsilon_{0}$-Yield displacement of energy dissipation steel bars), it shows that the damper yielded before the energy dissipation steel bar, this research is based on it. Mild steel dampers are used as the first line of defence against energy dissipation, and energy-consuming steel bars are used as the second line of defence against energy dissipation. Mild steel dampers act earlier than energy-consuming steel bars. The steel bars play a protective role to avoid premature yielding of energy-consuming steel bars, which is conducive to the continuous performance of the structure's seismic performance under aftershocks, which improves the safety performance of the structure, and the external mild steel dampers are easy to replace after earthquakes.

\section{Shear Capacity Analysis}

The shear force in the horizontal direction of the pier is mainly borne by the pier column itself, the horizontal component of the prestressed tendons, the friction between the bottom of the pier and the cap, and the horizontal component of the mild steel damper. The shear resistance mechanism as shown in Figure 5. 


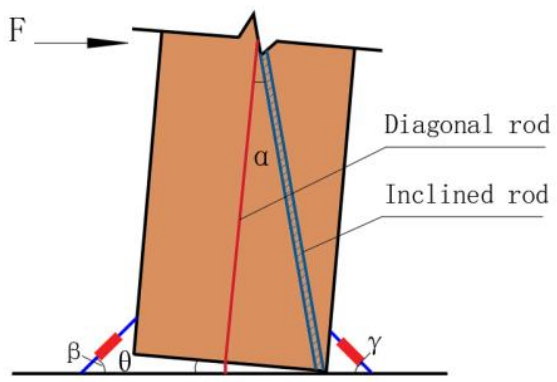

Fig. 5 - Shear Mechanism

When the angle between the pier bottom and the cap is $\theta$ under the horizontal force of the pier top, the compressed concrete of the pier column forms a compression rod, and the prestressed tendons form a tension rod. The shear capacity of the pier column is mainly divided into five parts, as Equation (5).

$$
V_{k}=V_{y}+V_{l}+V_{f}+V_{1}+V_{2}
$$

In Equation (5), $V_{k}$ is the shear bearing capacity of the pier column; $V_{y}$ is the horizontal component of the inclined rod; $V_{l}$ is the horizontal component of the diagonal rod; $V_{f}$ is the horizontal friction between the pier bottom and the cap; $V_{1}$ and $V_{2}$ are the horizontal components respectively force of the left and right mild steel dampers. Therefore, the above equation is referred to as Equation (6).

$$
V_{k}=0.8 f_{c} b_{2} b_{3} \cos \left(\frac{\pi}{2}-\alpha+\theta\right)+F_{p} \sin \theta+0.8 \mu f_{c} b_{2} b_{3} \sin \left(\frac{\pi}{2}-\alpha+\theta\right)+F_{1} \cos \beta+F_{2} \cos \gamma
$$

$b_{3}$ is evaluated empirically as

$$
0.2 \sqrt{h^{2}+\left(\frac{b_{1}}{2}\right)^{2}}
$$

In the above Equation, 0.8 is the concrete strength reduction factor; 0.2 is the constant coefficient; $f_{c}$ is the compressive strength of the concrete; $\mathrm{b}_{1}$ and $\mathrm{b}_{2}$ are the width of the bridge pier in the transverse and forward directions respectively; $b_{3}$ is the equivalent width of the diagonal strut; $F_{p}$ is the prestressed tendon Tensile force value; $\mu$ is the friction coefficient between the bottom of the pier and the cap, taking $0.5 ; F_{1}$ and $F_{2}$ are the axial tension and pressure values of the left and right mild steel dampers respectively; $\alpha$ is the angle between the line connecting the top of the column to the edge of the compressed concrete at the bottom of the column and the centre line of the pier column; $\beta$ and $\gamma$ are the angles between the left and right mild steel damper axis and the horizontal direction; $h$ is the height of the pier column. In general, $\theta$ is small, and the above equation is simplified as Equation (8).

$$
V_{k} \approx 0.8 f_{c} b_{2} b_{3} \sin \alpha+0.8 \mu f_{c} b_{2} b_{3} \cos \alpha+F_{1} \cos \frac{\pi}{4}+F_{2} \cos \frac{\pi}{4}
$$

Generally $\mathrm{b}_{1} / \mathrm{h} \leq 1$, therefore, $V_{y} \leq V_{f}$. Compared with the friction between the bottom of the pier and the cap, the shear capacity of the pier is mainly determined by the pier itself, as Equation (9).

$$
V_{k} \approx 0.8 f_{c} b_{2} b_{3} \sin \alpha+F_{1} \cos \frac{\pi}{4}+F_{2} \cos \frac{\pi}{4}
$$

The prefabricated self-resetting pier model with mild steel dampers designed by this research can get: $V_{k}=472 \mathrm{kN}$. The shear bearing capacity is much greater than the maximum horizontal force of $292 \mathrm{kN}$ in the simulation, so the designed pier shear capacity meets the requirements. 


\section{Model Parameters and Unit Selection}

In this paper, two sets of numerical models of bridge piers are established. The first group is M1, M2, M3 and M4. It mainly studies the influence of three mild steels with different yield strength parameters: BLY100, BLY160 and BLY225 [13-15] dampers on the seismic performance of the structure. The second group is M3, M5 and M6. Taking M3 pier as an example, the influence of axial compression ratio parameters of pier column on the seismic performance of the structure is mainly studied. The pier columns, caps, reinforcement, cross-sectional area of reinforcement, and prestressing tendons of the two groups of piers are the same, and the reinforcement ratio, energy dissipation steel, and prestressing tendons of the pier model are all based on the data in reference [7].

This paper used finite element software ABAQUS. The mild steel damper adopts hexahedral solid element and an ideal elastoplastic model. The main parameters of the model and the corresponding model numbers as shown in Table 1. M1 is a traditional assembled self-resetting pier. The concrete grade of each specimen is C60, the plastic damage model is adopted, the elastic modulus is $3.8 \times 10^{4} \mathrm{MPa}$, the Poisson's ratio is 0.3 , and the hexahedral solid element is adopted. The steel bar is HRB335, using truss elements, and an ideal elastoplastic constitutive model. The prestressed tendons are made of 1860 grade steel strands, and each prestressed tendon uses the cooling method to apply an initial prestress of $80 \mathrm{kN}$, and the expansion coefficient is set to $1.2 \times 10$ $5 /{ }^{\circ} \mathrm{C}$. The main parameters of each component of the structure as shown in Table 2 and Table 3 , the mechanical properties of reinforcement as shown in Table 4, and the reinforcement drawing of the assembled self-reset bridge pier with mild steel damper as shown in Figure 6.

Tab. 1 - Parameters of Mild Steel Damper

\begin{tabular}{|c|c|c|c|c|}
\hline Model number & Mild steel damper parts & Rebar model & Quantity & Axial compression ratio \\
\hline M2 & Mild steel rod & BLY100 & 10 & 0.026 \\
\hline M3 & Mild steel rod & BLY160 & 10 & 0.026 \\
\hline M4 & Mild steel rod & BLY225 & 10 & 0.026 \\
\hline M5 & Mild steel rod & BLY160 & 10 & 0.052 \\
\hline M6 & Mild steel rod & BLY160 & 10 & 0.078 \\
\hline
\end{tabular}

Tab. 2 - Main Design Parameters of Specimens

\begin{tabular}{|c|c|c|c|c|}
\hline Part name & $\begin{array}{c}\text { Part size/ } \\
(\mathrm{mm})\end{array}$ & Rebar specifications & $\begin{array}{l}\text { Number of } \\
\text { steel bars }\end{array}$ & Concrete strength \\
\hline \multirow{2}{*}{ Column size } & \multirow{2}{*}{$\begin{array}{c}400 \times 400 \times \\
1700\end{array}$} & $\begin{array}{l}\text { Longitudinal bar } \\
\text { HRB335 }\end{array}$ & $16 \Phi 12$ & \multirow{2}{*}{ C60 } \\
\hline & & Stirrup HRB335 & Ф6@60 & \\
\hline \multirow{2}{*}{ Cap size } & \multirow{2}{*}{$\begin{array}{c}1400 \times 700 \\
\times 500 \\
\end{array}$} & \multirow{2}{*}{ HRB335 } & Ф6@200 & \multirow{2}{*}{ C60 } \\
\hline & & & Ф6@150 & \\
\hline $\begin{array}{l}\text { Prestressed } \\
\text { tendons }\end{array}$ & 2200 & 1860 steel strand & 4 & \\
\hline
\end{tabular}


Tab. 3 - Main Design Parameters of Prestressed Tendons

\begin{tabular}{|c|c|c|c|c|}
\hline Part name & $\begin{array}{c}\text { Prestressed } \\
\text { tendons }\end{array}$ & Quantity & $\begin{array}{c}\text { Join forces/ (kN } \\
)\end{array}$ & $\begin{array}{c}\text { Single tension/ (kN } \\
\text { ) }\end{array}$ \\
\hline All models & Steel strand $\Phi 25$ & 4 & 320 & 80 \\
\hline
\end{tabular}

Tab. 4 - Mechanical Properties of Steel Bars

\begin{tabular}{|c|c|c|c|c|}
\hline Reinforced & $\begin{array}{c}\text { Elastic } \\
\text { modulus/(MPa) }\end{array}$ & $\begin{array}{c}\text { Yield } \\
\text { strength/(MPa) }\end{array}$ & $\begin{array}{c}\text { Ultimate } \\
\text { strength/(MPa) }\end{array}$ & Poisson's ratio \\
\hline BLY100 & $1.9 \times 10^{5}$ & 78 & 251 & 0.3 \\
\hline BLY160 & $1.9 \times 10^{5}$ & 123 & 262 & 0.3 \\
\hline BLY225 & $1.9 \times 10^{5}$ & 220 & 350 & 0.3 \\
\hline HRB335 & $2.02 \times 10^{5}$ & 353 & 493 & 0.3 \\
\hline Q345 & $2.1 \times 10^{5}$ & 345 & 550 & 0.3 \\
\hline
\end{tabular}

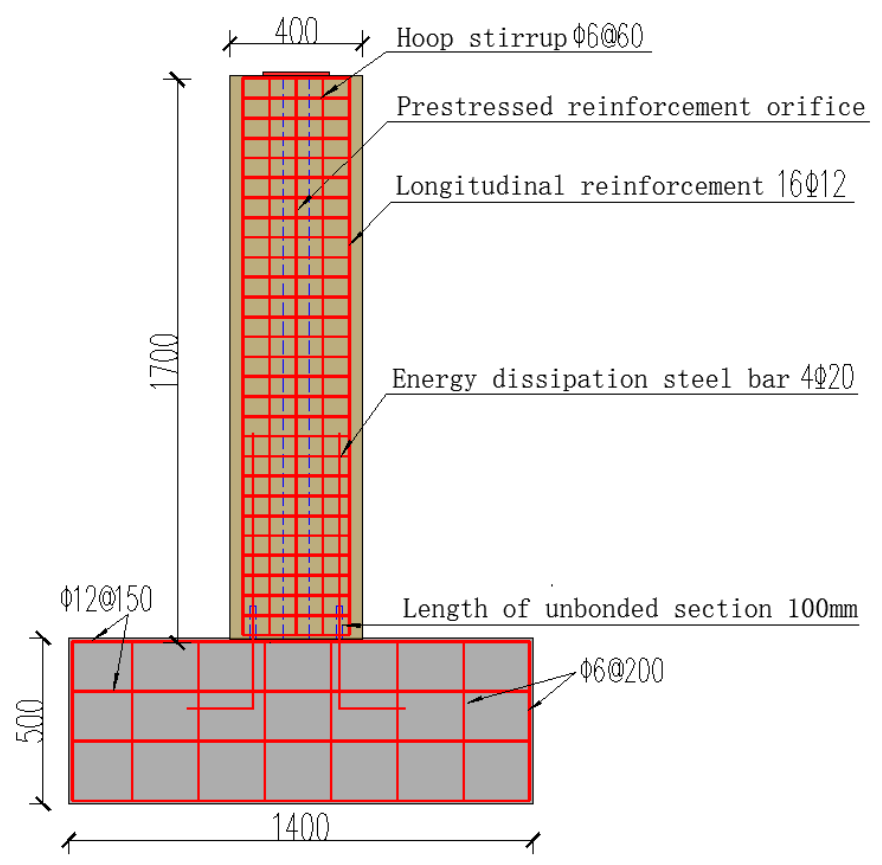

Fig. 6 - Reinforcement Diagram of Pier with Additional Mild Steel Damper

\section{Boundary Conditions and Loading System}

The bottom of the cap is fixed, and the bottom of the cap and the upper pier adopts surfaceto-surface contact, and the contact characteristics of the normal direction and the tangent direction are set. The tangent direction adopts the Coulomb friction model, the friction coefficient is 0.5 , and the normal direction is "hard" contact. The contact relationship between the concrete and the steel bar is assumed to ignore the bond-slip effect, and the steel bar is incorporated into the designed concrete member. The prestressed tendons are combined with the steel plate into a whole, which 
binds the upper steel plate to the top of the pier, and the lower steel plate to the bottom of the cap. Rigid connection is adopted between the mild steel damper support and the bridge pier, cap and between the soft steel rod and the shaft and sleeve, which are set as binding constraints. The shaft, sleeve and support are hinged by high-strength bolts, and the contact surfaces adopt surface-tosurface contact, regardless of the Coulomb friction between the contact surfaces. Numerical experiments are used to control the horizontal displacement of the low-cycle reciprocating loading form to simulate the cyclic reciprocating motion of the bridge pier under the action of an earthquake.

Before low-cycle reciprocating loading, apply a concentrated load of $220 \mathrm{kN}, 440 \mathrm{kN}, 660 \mathrm{kN}$ on the top of the pier to simulate the vertical load from the superstructure, corresponding to M3, M5, M6 piers with different axial compression ratios, and add pier column structure self-respect. Couple a reference point on the top surface of the pier, and apply a reset movement to the reference point. The model loading diagram is shown in Figure 7. The maximum load displacement is $60 \mathrm{~mm}$, the grading load, the first level is $5 \mathrm{~mm}$, the second level is $10 \mathrm{~mm}$, the third level is $15 \mathrm{~mm}$, and so on, each level is increased by $5 \mathrm{~mm}(0.3 \%)$, and each level is repeated 3 times. The loading method is shown in Figure 8.

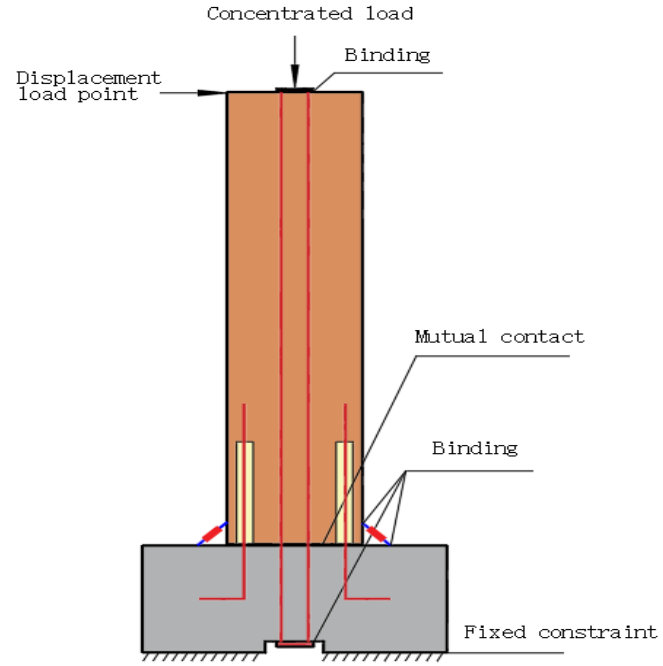

Fig. 7 - Loading diagram

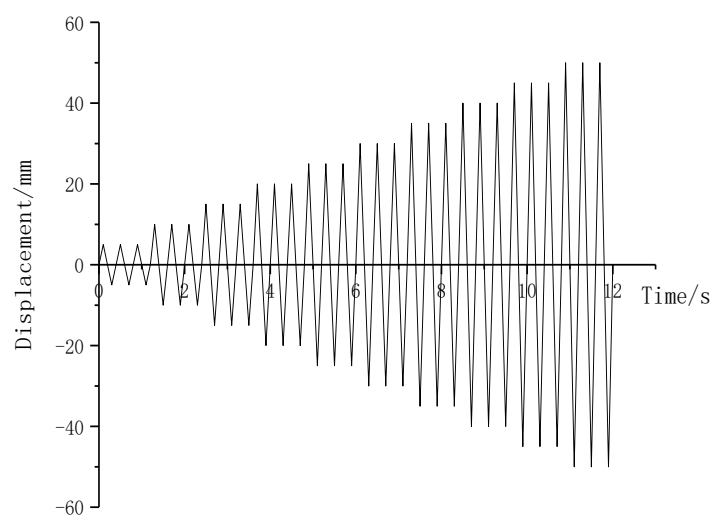

Fig. 8 - Loading method

\section{Numerical Model Verification}

The numerical model established in accordance with the traditional prefabricated selfresetting pier in the test in Reference [7] is subjected to low-cycle repeated loading, and the forcedisplacement curve is obtained, which is compared with the existing test results, as is shown in Figure 9. The force-displacement curve obtained based on the numerical test is basically consistent with the test result. Because the energy-dissipating steel bar in the numerical calculation adopts an ideal elastoplastic constitutive model, and does not consider the strengthening effect of the actual steel bar force, the ultimate bearing capacity is slightly lower than the results obtained from the test. 


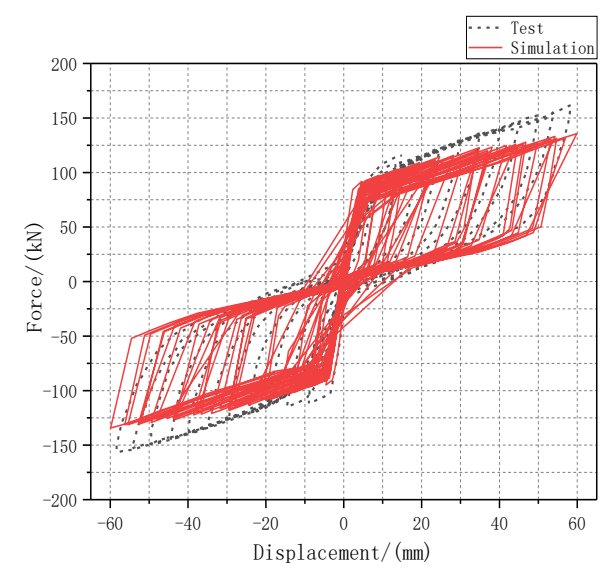

Fig. 9 - Force - Displacement Curve of M1

\section{RESULTS AND ANALYSIS}

\section{Comparison of Hysteresis Curves of Bridge Piers with Mild Steel Dampers}

The hysteresis curve is of great significance to the analysis of the seismic performance of structures or components, and comprehensively reflects its seismic performance. The comparison of hysteresis curves is shown in Figure 10.

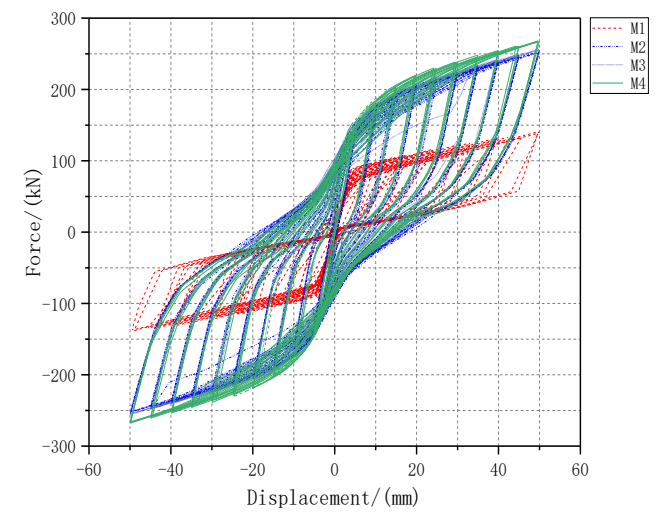

(a) Hysteresis Curve of M2,M3,M4 and M1

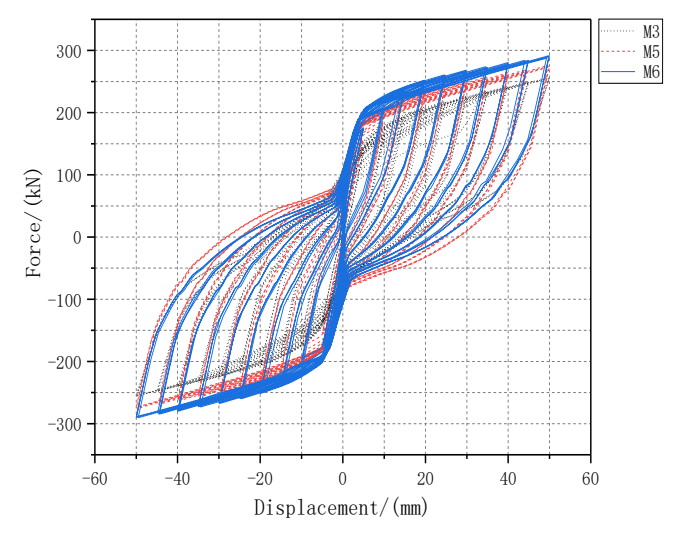

(b) Hysteresis Curve of M3,M5 and M6

Fig. 10 - Hysteresis Curve

In Figure 10(a), the following conclusions can be drawn: (1) Compared with M1 piers, the force-displacement curves of M2, M3, and M4 piers are generally shuttle-shaped, with a more full shape, and the energy consumption and bearing capacity have been improved to a certain extent. The mild steel dampers have a good seismic effect. (2) The force-displacement curves of M2, M3, and M4 piers are similar, indicating that the three have similar mechanical properties. In the initial stage of loading, the structure is in the elastic stage. As the displacement loading progresses, the hysteresis loop area continues to increase and consumes energy. The stiffness of the specimen is gradually degraded. At the later stage of loading, the structural force-displacement curve is gradually full and pinch phenomenon appears, indicating that the prestressed tendons have played a good role. 
In Figure 10(b), as the pier-column axial compression ratio increases, the hysteresis curve of the structure becomes fuller, the bearing capacity and energy consumption capacity are improved, and the residual displacement increases.

\section{Analysis of Energy Dissipation Capacity of Bridge Piers with Mild Steel Dampers}

Energy dissipation capacity is of great significance for measuring the seismic performance of structural members. It is generally represented by the graphic area enclosed by the loaddisplacement curve envelope. By analyzing the hysteresis curve of the structure, the cumulative energy consumption of the structure can be calculated quantitatively. The cumulative energy consumption of the study is the superposition of the average value of the hysteresis loop area of 3 cycles per load displacement. The energy consumption curve as shown in Figure 11.

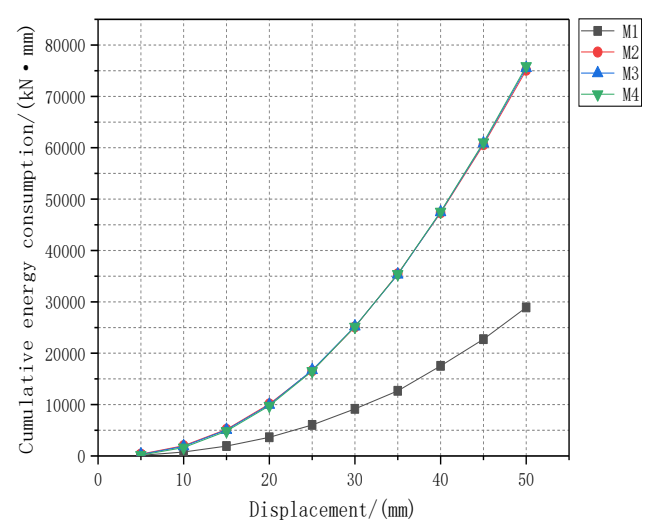

(a) Energy Dissipation Curve of M2,M3,M4 and M1

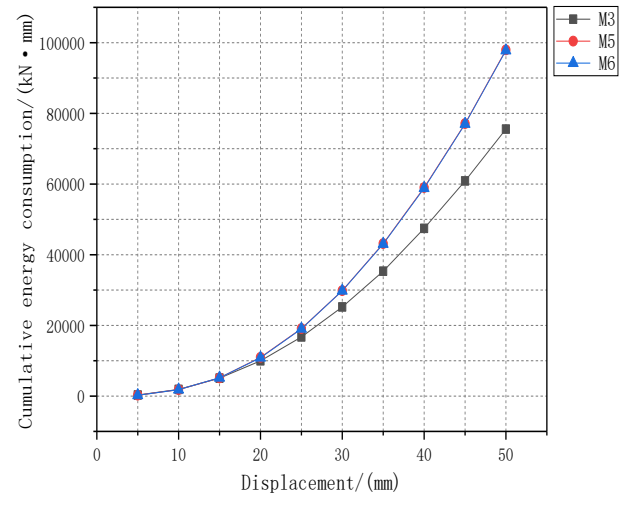

(b) Energy Dissipation Curve of $M 3, M 5$ and $M 6$

Fig. 11 - Energy Dissipation Curve

In Figure 11(a), as the loading displacement gradually increases, the cumulative energy consumption of piers gradually increases. Compared with traditional piers M1, M3 piers, the maximum cumulative energy consumption value is increased by 2.5 times. The energy consumption capacity is better than that of traditional fabricated self-resetting piers.

In Figure 11(b), compared to M3, the cumulative energy consumption value of M5 piers has increased by $30 \%$, while the energy consumption capacity of M5 and M6 piers is not much different, indicating that increasing the axial compression ratio of the pier column within a certain range can be improve the energy consumption capacity of the bridge pier, when the axial compression ratio exceeds 0.052 , the effect is not obvious.

Figure 12 shows the ratio of the energy consumption of mild steel dampers to the total energy consumption. 


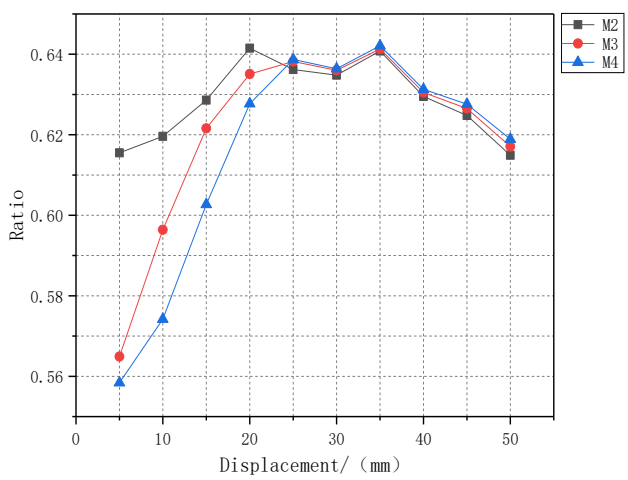

(a) Comparison of Energy

Dissipation Ratio of M2,M3 and M4 Mild Steel Dampers in Total Energy Dissipation

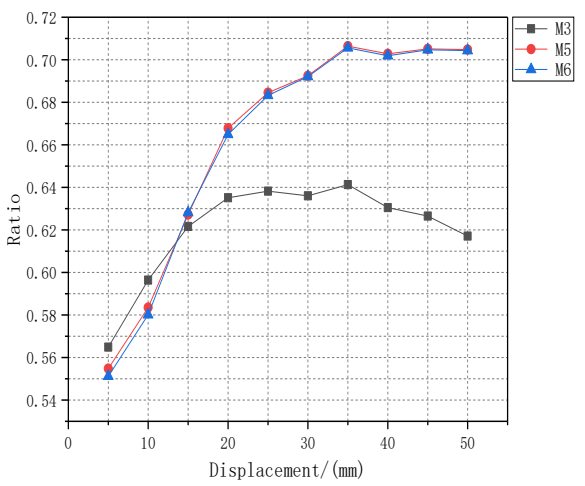

(b) Comparison of Energy Dissipation Ratio of M3,M5 and M6 Mild Steel Dampers in Total Energy Dissipation

Fig. 12 - Proportion of Energy Dissipation of Mild Steel Dampers

In Figure 12(a), the ratio of the energy consumption of the three types of mild steel dampers with different yield strengths to their total energy consumption gradually increases with the load of displacement, and they are all greater than 0.55, indicating that the external mild steel dampers are effective improve the energy consumption capacity of bridge piers. When the horizontal displacement load is less than $25 \mathrm{~mm}$, the M2 pier mild steel dampers account for the largest energy consumption, and the cumulative energy consumption value is the largest, and the M4 pier has the smallest value. When the horizontal displacement load is greater than $25 \mathrm{~mm}$, the M4 pier mild steel dampers account for the largest energy consumption, and the cumulative energy consumption value is the largest, and the M2 pier the above value is the smallest, indicating that with the increase of the mild steel damper yield strength, when the loading displacement is small , the ratio of the energy consumption of the mild steel dampers to the total energy consumption gradually decreases, and the cumulative energy consumption value of the bridge piers decreases. When the loading displacement is large, the energy consumption of the mild steel damper gradually increases, and the cumulative energy consumption value of the pier increases. Therefore, in order to increase the overall energy consumption of the pier, the yield strength of the mild steel damper cannot be increased indefinitely, and the energy dissipation capacity of the structure under small displacement loading must also be considered. In contrast, M3 piers with BLY160 mild steel dampers have the best seismic performance. In order to make the structure have a more sustainable and stable energy dissipation capacity, the energy sharing ratio between the mild steel damper and the energy dissipation steel bar when the horizontal loading displacement limit value is $25 \mathrm{~mm}$ is taken as the best sharing ratio, and the calculated ratio is 1.75 .

In Figure 12(b), when the loading displacement is less than $13 \mathrm{~mm}$, as the axial compression ratio of the pier column increases, the energy consumption of the mild steel damper gradually decreases. When the loading displacement is greater than $13 \mathrm{~mm}$, the energy consumption of the mild steel dampers of the M5 and M6 piers gradually increases and exceeds that of the M3 pier. They are in a stable state at the later stage of the displacement loading, indicating that in the middle and late loading displacements, the pier column axis is within a certain range The larger the pressure ratio, the better the energy dissipation effect of the mild steel damper. The energy consumption ratio of the mild steel dampers of M5 and M6 piers is basically similar in the middle and later stages of displacement loading, indicating that the effect of the pier-column axial compression ratio exceeds a certain range is not obvious. Consider the energy consumption of the mild steel dampers when the loading displacement is small. The recommended value of pier column axial compression ratio is 0.052 . 


\section{Comparison of Stiffness Degradation of Piers with Mild Steel Dampers}

Stiffness degradation is a phenomenon that the peak point displacement increases with the increase of the number of cycles when the same peak load is maintained under cyclic loading, and the formula for stiffness degradation as Equation (10).

$$
K_{i}=\frac{\sum_{i=1}^{n} P_{j}^{i}}{\sum_{i=1}^{n} \Delta_{j}^{i}}
$$

In Equation (10), $K_{i}$ is the ring stiffness of the structure; the numerator is the peak load of the $\mathrm{i}$-th cycle; $\Delta$ is the deformation value at the maximum point of the $\mathrm{i}$-th cycle; $\mathrm{n}$ is the number of times. The stiffness degradation curve as shown in Figure 13.
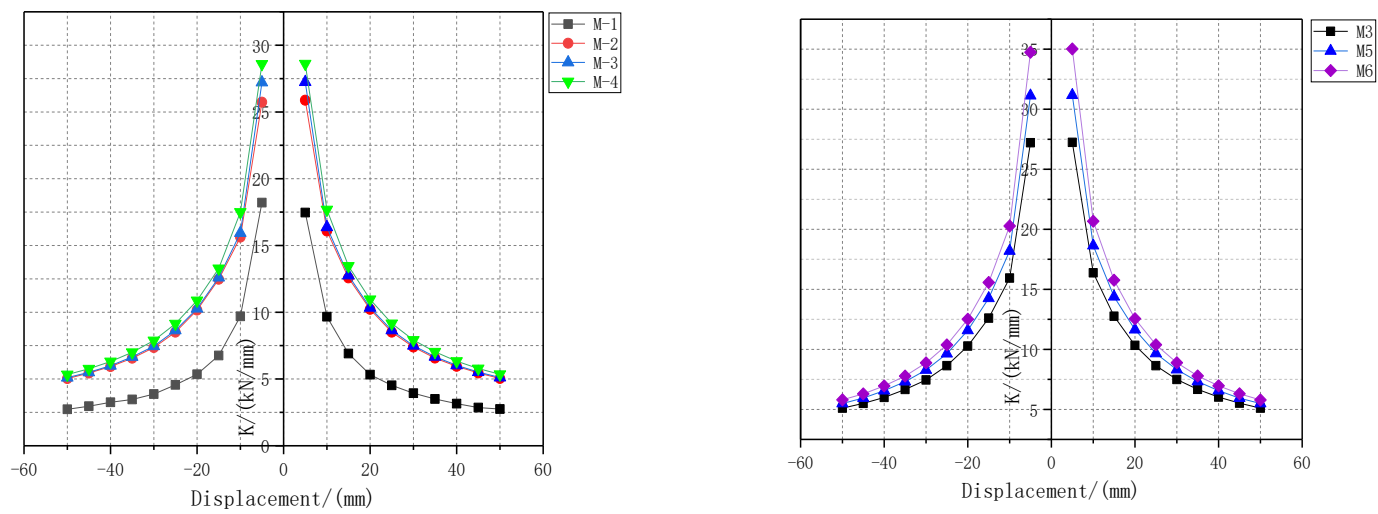

Fig. 13 - Stiffness degradation curve

The stiffness degradation is roughly symmetrical, and the stiffness degradation is more obvious and uniform. The stiffness degradation of the $M 2, M 3$, and M4 piers is relatively similar, showing similar mechanical properties. Compared with traditional prefabricated self-resetting piers, the rigidity of the prefabricated self-resetting piers with external mild steel dampers is greater, because the mild steel dampers increase the initial rigidity of the pier. The stiffness of the pier with the external mild steel damper decreases with the increase of the horizontal displacement, the descent rate is almost the same, and the slope of the stiffness curve gradually decreases. It shows that the stiffness of the assembled self-resetting pier with external mild steel dampers is obviously degraded, continuous and stable, and there is no damage to the structure due to the sudden decrease. The increase of the pier-column axial compression ratio improves the initial stiffness of the pier, but the axial compression ratio parameter has little effect on the overall stiffness degradation of the pier.

\section{Comparison of Residual Displacement of Bridge Piers with Mild Steel Dampers}

The variation of the pseudo-static residual displacement of the specimen with the load displacement level as shown in Figure 14. 


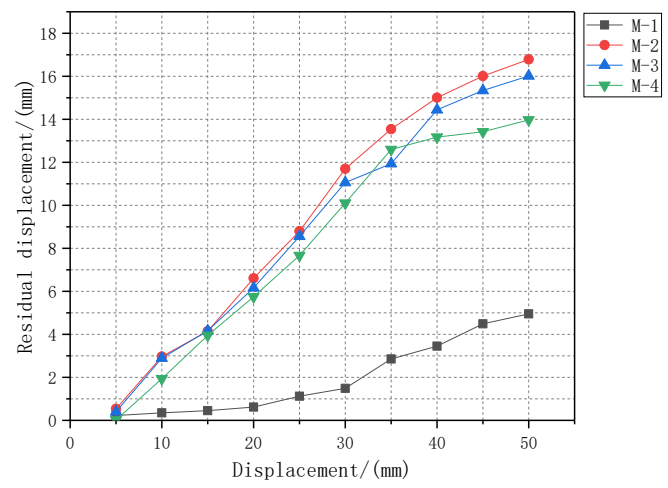

Fig. 14 - Residual Displacement Curve of M2,M3,M4 and M1

Under the action of low-cycle reciprocating load, compared with traditional prefabricated selfresetting piers, the residual displacement of self-resetting piers with additional mild steel dampers has increased. This is because the external mild steel dampers increase the unloading rigidity of the pier. Cause the residual displacement to increase. According to the reference [16], in order to make the piers repairable after the earthquake without reconstruction, it is necessary to ensure that the residual displacement angle of the pier after the earthquake does not exceed $1 \%$. The maximum residual displacement of the $\mathrm{M} 2, \mathrm{M} 3$, and $\mathrm{M} 4$ piers is $16.7 \mathrm{~mm}$, which meets the requirement that the residual displacement angle is less than $1 \%$. The residual displacement curves of M2, M3, and M4 piers have roughly the same trend. The residual displacement of M4 piers is smaller, indicating that the greater the yield strength of the mild steel dampers within a certain range, the better the selfresetting ability of the piers, but the difference is not much.

The text defines the self-resetting coefficient to measure the self-resetting ability of the structure. The larger the value, the better the self-resetting ability of the structure. Generally, $0 \leq \eta \leq 1$. The self-resetting coefficient is determined by Equation (11).

$$
\eta=1-\frac{\Delta_{i}}{\Delta_{j}}
$$

In Equation (11), $\Delta_{i}$ is the residual displacement of the structure after loading; $\Delta_{j}$ is the maximum displacement of the structure in the same load cycle. The comparison of self-reset coefficients under different axial compression ratios is shown in Figure 15.

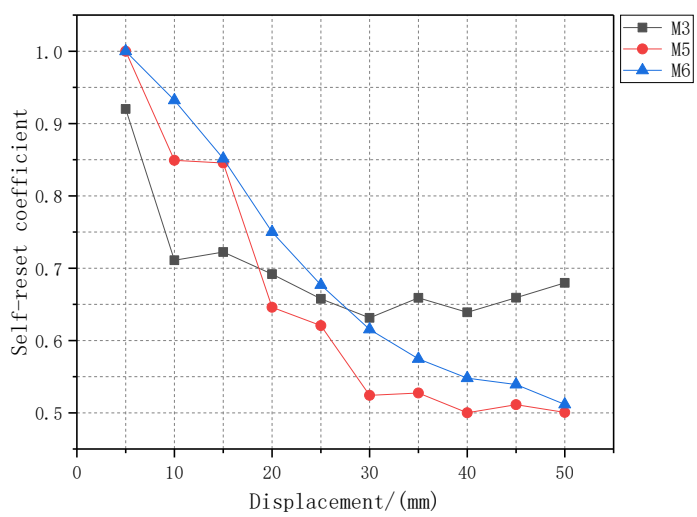

Fig. 15 - Self-Reduction Coefficient of M3,M5 and M6 
In the initial stage of displacement loading, increasing the pier-column axial compression ratio within a certain range can improve the self-reset capability of the structure. In the later stage of displacement loading, the self-reset ability of the structure is reduced. It shows that the increase of the pier-column axial compression ratio makes the mild steel damper enter the fully yielding energy dissipation state earlier, resulting in greater residual deformation at the later stage of displacement loading. The self-reset coefficient curves of M5 and M6 are similar, indicating that the influence of the pier-column axial compression ratio exceeds a certain range is not obvious.

\section{CONCLUSION}

In this study, the numerical test method was used to compare the response analysis and comparison of the fabricated self-resetting piers with additional mild steel dampers and the traditional fabricated self-resetting piers under low-cycle reciprocating loads. The effects of the yield strength parameters of mild steel dampers and the axial compression ratio parameters on the seismic performance of the bridge piers are studied. Concluded as follow:

(1) Fabricated self-resetting piers with external mild steel dampers have good self-resetting ability, high bearing capacity and energy dissipation capacity, and have good seismic performance under low-cycle repeated loads.

(2) Within a certain range, the greater the yield strength of the mild steel damper, the greater the bearing capacity, the better the overall energy dissipation capacity, and the smaller the residual displacement. When the loading displacement is less than $25 \mathrm{~mm}$, the greater the yield strength of the mild steel damper, the smaller the proportion of energy consumption. In contrast, BLY160's prefabricated self-reset bridge pier has the best seismic performance, and the optimal energy dissipation ratio between the mild steel damper and the energy-dissipating reinforcement is 1.75.

(3) The greater the axial compression ratio of the pier column in a certain range, the greater the energy consumption, bearing capacity of the structure, when the loading displacement is small, the self-reset ability of the structure is better, and when the loading displacement is large, the mild steel damper enters the full yielding energy consumption state earlier. When the axial compression ratio exceeds a certain range, the effect is not obvious. In contrast, the recommended value of pier column axial compression ratio is 0.052 .

(4) The external mild steel damper yields before the energy-dissipating steel bars to protect the energy-dissipating steel bars and avoid premature yield failure of the energy-consuming steel bars, which is conducive to the continuous development of the seismic performance of the structure under aftershocks, and its easy replacement feature is conducive to post-earthquake repair.

\section{ACKNOWLEDGEMENTS}

This paper is subsidized by the National Natural Science Foundation of China (51378169) and Key Project of Science and Technology Research in Hebei Province (ZD2016147)

\section{REFERENCES}

[1] MANDER J B, CHENG C T. Seismic resistance of bridge piers based on damage avoidance design[R]. Technical Report NCEER-97-0014. Buffalo: State University of New York at Buffalo, 1997.

[2] SOLBERG K, MASHIKO N, MANDER J B, DHAKAL R P. Performance of a damage-protected highway bridge pier subjected to bidirectional earthquake attack [J]. Journal of Structural Engineering, ASCE, 2009, 135(5): 469-478.

[3] MARRIOTT D, PAMPANIN S, PALERMO A. Quasi-static and pseudo-dynamic testing of unbonded post-tensioned rocking bridge piers with external replaceable dissipaters [J]. Earthquake Engineering and Structural Dynamics, 2009, 38(3): 331-354. 
[4] MARRIOTT D, PAMPANIN S, PALERMO A. Biaxial testing of unbonded post-tensioned rocking bridge piers with external replacable dissipaters [J]. Earthquake Engineering and Structural Dynamics, 2011, 40(15): 1723-1741.

[5] TRONO W, JEN G, PANAGIOTOU M, SCHOETTLER M, OSTERTAG C P. Seismic response of a damage-resistant recentering posttensioned-HYFRC bridge column [J]. Journal of Bridge Engineering, ASCE, 2015, 20(7): 1-13.

[6] HE M H, XIN K G, GUO J et al. Study on intrinsic lateral stiffness and hysteresis mechanism of selfreposition bridge piers [J]. China railway science, 2012, 33(05): 22-28. (in Chinese)

[7] GUO J, XIN K G, HE M H et al. Experimental research and analysis on seismic performance of selfrestoring bridge piers [J]. Engineering mechanics, 2012, 29(S1): 29-34+45. (in Chinese)

[8] HAITHAM D, MOHAMED E, JOSHUA H. Behavior of segmental precast posttensioned bridge piers under lateral loads [J]. Journal of Bridge Engineering, 2012, 17(5): 735-746.

[9] BU Z Y, OU Y C, SONG J W, et al. Cyclic Loading Test of Unbonded and Bonded Posttensioned Precast Segmental Bridge Columns with Circular Section [J]. Journal of Bridge Engineering, 2015, 21(2): 10 18.

[10] WANG J W, ZHANG W G, AI Q H. Comparison of seismic performance tests of PC and RC Hollow Piers [J]. Journal of China highway, 2015, 28(04): 76-85. (in Chinese)

[11] GAO J, GE J P, LIN T L. Quasi static test research on dry joint segmental assembled piers [J]. Vibration and impact, 2011, 30(04): 211-216. (in Chinese)

[12] GUO T, CAO Z, XU Z, et al. Cyclic Load Tests on Self-centering Concrete Pier with External Dissipators and Enhanced Durability[J]. Journal of Structural En-gineering, 2015, 142(1): 10-19.

[13] WANG M, QIAN F X, YANG W G, YANG L. Comparison study on constitutive relationship of low yield point steels, Q345B steel and Q460D steel [J]. Eengineering mechanics, 2017, 34(02): 60-68. (in Chinese)

[14] CHEN Z Y, MAI C L, XU Z X, et al. Experimental research on seismic performance of shear plate damper made by low yield point steel [J]. J Xiamen Univ Nat Sci, 2019, 58(06): 916-921. (in Chinese)

[15] SONG F M, WEN D H, LI Z G. Development of 225MPa low yield point steel used for earthquake resistant [J]. Thermal processing technology, 2009, 38(12):62-63+69. (in Chinese)

[16] JAPAN ROAD ASSOCIATION (JRA). Design specifications of highway bridges: seismic design (JRA2012)[S]. Tokyo: Japan Road Association, 2012. 